\title{
Alteridades estranhadas: contradições e potencialidades da forma ser-outra no capitalismo vigente
}

\author{
Tábata Berg (https://orcid.org/0000-0002-7467-6033), \\ Departamento de Ciências Sociais da Universidade \\ Federal de Viçosa (UFV), Minas Gerais, Brasil'.
}

Recebido: 27.07.20 Aprovado: 14.05 .21

\author{
I. Tábata Berg \\ é doutora pelo \\ Programa de \\ Pós-Graduação \\ em Sociologia \\ da Universidade \\ Estadual de \\ Campinas (Unicamp), \\ São Paulo, Brasil, \\ e professora no \\ Departamento de \\ Ciências Sociais da \\ UFV, Minas Gerais, \\ Brasil. Mãe desde \\ 2016. \\ <tabataberg@yahoo. \\ com.br>.
} formas laborais não remuneradas são basilares às cadeias radicais do capitalismo.

Palavras-chaves: Ser-outra. Capitalismo. Patriarcado. Escravidão. Trabalho não remunerado.

\section{Strange alterities:}

\section{contradictions and potentialities of the}

being-other-woman form in current capitalism

\begin{abstract}
The purpose of this proposal is to launch a decolonial feminist perspective on capital accumulation, shifting the emphasis on the capital / labor (wage earner) relationship to the forms of non-wage labor exploitation and oppression; namely those that developed inherent to racist patriarchy through the overlap between colonialism, patriarchy and slavery. To this end, the article will cover different ways of being-other-woman, a category that I have been articulating and which I present here an outline. The aim is to launch a feminist perspective, starting from listening to peripheral and feminist voices, to continue radicalizing the question that, even marginal, was not absent from the concerns of Marxism in its diversity: about how the various unpaid forms of work are fundamental to the radical chains of capitalism.
\end{abstract}

Keywords: Being-other-woman. Capitalism. Patriarchy. Slavery. Unpaid work. 
$\bigwedge$ que

quele homem ali diz que as mulheres Aprecisam de ajuda para entrar em carruagens, e devem ser carregadas para atravessar valas, e ter o melhor lugar onde quer que estejam. Ninguém jamais me ajudou a entrar em carruagens, ou a saltar sobre poças de lama, e nunca me deram melhor lugar algum! Não sou eu uma mulher? Olhem para mim? Olhem para meus braços! Eu arei e plantei, e juntei a colheita nos celeiros, e homem nenhum poderia me dirigir. Não sou eu uma mulher? Eu poderia trabalhar tanto e comer tanto quanto um homem - quando eu pudesse consegui-lo - e suportar o chicote também! Não sou eu uma mulher? Eu pari treze filhos e vi a maioria deles ser vendida para a escravidão, e quando eu clamei com a minha dor de mãe, ninguém a não ser Jesus me ouviu! Não sou eu uma mulher? [...] Daí aquele homenzinho de preto ali disse que a mulher não pode ter direitos como os homens, porque Cristo não era mulher! De onde o seu Cristo veio? De onde o seu Cristo veio? De Deus e de uma mulher! O homem não teve nada a ver com ele. Se a primeira mulher que Deus fez foi forte o bastante para virar o mundo de cabeça para baixo sozinha, todas estas mulheres juntas devem ser capazes de consertá-lo, colocando-o do jeito certo novamente. E agora que elas estão pedindo para fazer isso, é melhor que os homens as deixem fazer.

Agradecida a vocês por me escutarem, e agora a velha Sojourner não tem mais nada a dizer.

Discurso "Ain't I a woman?", de Sojourner Truth, Convenção de mulheres, Akro, Ohio, 1851.

N este artigo, sugiro que percorramos alguns modos distintos de ser-outra que, como pretendo explicitar, são basilares à gênese e ao desenvolvimento do capitalismo vigente, bem como às formas plurais de autorreflexão a partir das posições de alteridades. Ser-outra é uma categoria que venho desenvolvendo para compreender o sistema capitalista a partir de uma visada feminista decolonial. 
De acordo com Marx (2013: 307), o capitalismo é um modo de produção impessoal, seus agentes são "apenas capital personificado. Sua alma é a alma do capital". No entanto, ao longo de seu desenvolvimento, essa personificação tem sido protagonizada por sujeitos, em sua maioria masculinos, brancos e do Norte global ${ }^{1}$.

Proponho, neste artigo, lançar um olhar ao capitalismo, partindo das alteridades que, embora subalternas, garantem seu funcionamento: o capital necessita, ao custo de extinguir-se, de um outro diferente ontologicamente, na forma de ser, de si mesmo, tanto para expropriá-lo como para realizar-se e, somente assim, ampliar-se. Portanto, capitalismo e colonialidade estão em relação de consubstancialidade (Vergès, 2020). A esse outro plural, essencial ao absolutismo capitalista, estou conceituando por ser-outra.

Mobilizo a perspectiva reiterada por diversas intelectuais negras desde as lutas abolicionistas e anticoloniais, para as quais não é possível hierarquizar as formas de opressão e exploração; todavia, as experiências coletivas são diversas, em detrimento da localização nas relações sociais (Collins, 2019; Ribeiro, 2019; Vergès, 2020).

Compreender, cada vez mais, a diversidade das formas de estranhamento (Ranieri, 2001), a ser-outra em sua multiplicidade, possibilita seguir esmiuçando o modus operandi do capitalismo, sua coerência interna e suas contradições; ao mesmo tempo que compreender as resistências decoloniais que lhe fazem constante oposição nos oferece subsídios imaginativos com os quais podemos seguir construindo as possibilidades concretas de sua superação. Neste artigo, debruçar-me-ei sobre as formas de estranhamento e as resistências a partir de uma perspectiva dialética, partilhando da concepção de Françoise Vergès (2020), para quem os feminismos decoloniais

colocam à disposição das lutas que partilham o objetivo de reumanizar o mundo, a sua biblioteca de saberes, sua experiência de práticas, suas teorias antirracistas e antissexistas, incansavelmente associadas às lutas anticapitalistas e anti-imperialistas (Vergès, 2020: 46).

Em White woman listen! Black feminism and the boundaries of sisterhood, Hazel Carby afirma que "três conceitos centrais da teoria feminista se tornam problemáticos em sua aplicação à vida das mulheres negras: 'a família', 'o patriarcado' e 'a reprodução'” (Carby, 1997: 112, tradução livre), questionando a transposição universal desses conceitos que foram majoritariamente constituídos a partir das experiências de opressão sofridas por mulheres brancas, europeias e das classes médias.
1. Na lista dos que estão entre as dez pessoas mais ricas do globo em 2020, e dos que tiveram aumento de suas fortunas durante a pandemia de Covid-19, ainda em curso, todos são homens brancos e do Norte global. Dados que são ainda mais significativos em um contexto no qual $1 \%$ da população mundial detém metade das riquezas do planeta. Disponível em: <https://brasil.elpais. com/economia/ 2021-01-01/ pandemia-faz-asmaiores-fortunas-doplaneta-dispararem. html>. Acesso em: 24 Mar. 2021. 
Generalizações e projeções silenciam as particularidades, caráter ativo para a estruturação concreta do capitalismo, fabulando, para usar o termo de Achille Mbembe (2018), presenças constantes de resquícios de um patriarcado pré-moderno, do qual é preciso resgatar a(s) mulher(es) colonizada(s), de modo a incorporá-las aos avanços e às conquistas das quais pretensamente usufruem as mulher(es) ocidentais; estas mulheres, de fato, partícipes da história das mulheres.

É o mecanismo da história única sobre o qual nos alerta Chimamanda Ngozi Adichie (2009: 27): "A consequência da história única é esta: ela rouba a dignidade das pessoas." Ofusca as relações coloniais/imperialistas/patriarcais racializadas - capitalistas - e vitimiza a(s) mulher(es) colonizada(s) - negra(s), indígena(s), latina(s), muçulmana(s), entre tantas mais -, percebidas enquanto ser-outras, ao mesmo tempo em que transfere a responsabilidade por nossa opressão e exploração às instituições e relações societais e familiares retrógradas, nas quais a(s) mulher(es) se encontram pretensamente inseridas: legitimando a ordem capitalista colonial/ imperial. É quando a herstory trabalha para a história, cuja pretensão era reescrever, subverter, quando parte do feminismo é cooptado pelos interesses coloniais. Françoise Vergès alerta para a cumplicidade ativa que o feminismo civilizatório tem realizado em relação à expropriação, à exploração e à opressão das mulheres racializadas, colonizadas e das classes populares, empreendidas pelo capitalismo racial, desempenhando um importante papel de apagamento das lutas anticoloniais e anti-imperialistas das mulheres do Sul global (Vergès, 2020: 39 e 85).

No artigo, a categoria patriarcado terá lugar de centralidade para a compreensão do processo de estruturação da forma ser-outra no capitalismo, a partir da qual, família e (re)produção também serão analisadas e, sobretudo, repensadas. Para escapar de uma herstory unilateral e branca, colonizadora, dialogarei com teóricas feministas que se debruçaram sobre tais categorias, a partir de posições e condições plurais da ser-mulher(es); ao mobilizar as reflexões das intelectuais negras e indígenas para percorrer caminhos distintos do processo de exploração e opressão capitalistas, sob cujas mulher(es) tornamo-nos ser-outras, a escuta, tal como desenvolvida por Hazel Carby (1996), será o método privilegiado de análise.

Estou compreendo a escuta como método de análise articulado à standpoint theory de Patrícia Hill Collins (2019). De acordo com a autora, "cada grupo social tem uma visão de mundo em constante evolução que utiliza para ordenar e avaliar suas próprias experiências" (Collins, 2019: 44). Portanto, os grupos marginalmente inseridos na sociedade capitalista, como as mulheres negras e indígenas, ao se ancorarem de modo dialético em suas experiências coletivas, constroem teorias distintas daquelas legitimadas dentro do pensamento acadêmico ocidental (Collins, 2019: 
44). Pelo fato de a experiência da opressão ser um elemento articulador dessas epistemologias, incorporá-la requer um método de escuta ativa, uma vez que a relação sujeito cognoscente/objeto de conhecimento é atravessada pela inserção dos grupos marginalizados no polo do objeto, subalternizando seus saberes. Pela interlocução, a escuta como método tem por objetivo romper com a reprodução dessa estrutura hierárquica do processo cognoscente. Assim, a escuta como método tem por objetivo minimizar essas distorções e conceder-me, concomitantemente, os instrumentos capazes de apreender, na multiplicidade de posições e condições, como o patriarcado racista tem se constituído desde a acumulação primitiva de capitais em importante pilar da expropriação capitalista.

Contudo, é preciso ressaltar que a escuta não é um processo mecânico. É sempre mediada pelas experiências, isto é, pelo lugar de fala da ouvinte, de tal modo que mesmo quando utilizo - e o faço com frequência - citações diretas, elas são uma interpretação dessas vozes, cujas relações de opressão e exploração racializadas não deixam de impactá-la.

O intuito deste artigo, portanto, é rascunhar, a partir da categoria ser-outra, como gênero e raça (assim como outras tantas alteridades mobilizadas), longe de se configurarem em meros aspectos ideológicos, podendo encontrar superação dentro do sistema capitalista, são basilares ao seu desenvolvimento.

\section{A lei é não remunerar: \\ escravidão e patriarcado enquanto protoformas articuladas da ser-outra}

Angela Davis (2016) ressalta que embora Sojourner Truth e tantas outras personagens negras, cujas histórias de vida sua obra analisa, fossem individualmente espetaculares, carregavam consigo características de resistência e visão de mundo comuns à experiência coletiva dos povos negros escravizados, tendo como um de seus "feitos mais impressionantes" - herança transmitida por gerações - a transformação ativa da igualdade negativa, experimentada através do nivelamento brutal entre trabaIhadoras escravas, escravos e crianças, forjada no trabalho forçado e na repressão violenta, em igualdade substantiva no âmbito doméstico. As mulheres negras escravizadas - afirma Davis - experimentaram o reconhecimento mútuo de seus pares, construindo uma alteridade reconhecida na ferocidade da alteridade absoluta.

A igualdade negativa à qual as mulheres negras estiveram submetidas no exercício de sua atividade laboral produtiva (aos senhores e à acumulação de capital), radicalmente estranhada, pôde transformar-se, pela ação dessas mulheres, em igual- 
dade positiva no colo acolhedor e criativo do trabalho re(produtivo): o trabalho doméstico partilhado entre mulheres, homens e crianças de forma complementar, possibilitou a criação de laços de solidariedade e pujantes relações familiares que se contrapunham a toda violência e degradação da escravidão (Davis, 2016: 30).

Essa igualdade, em alguma medida, experimentada pelas trabalhadoras escravizadas - seja em sua dimensão negativa, seja na dimensão positiva - conformou uma feminilidade bastante distinta daquela compartilhada pelas mulheres brancas das classes médias e proprietárias e, até mesmo, daquela vivida pelas proletárias livres. Uma feminilidade que em nada trazia a fragilidade - pretensa marca de nossa natureza inferior, destino de cuja condenação divina e biológica nos seria impossível escapar.

Ao mesmo tempo, os laços construídos no exercício do trabalho doméstico configuram a feminilidade como complementar à masculinidade. Nesse contexto, a solidariedade entre homens e mulheres escravizadas apresentava-se como perigo para a supremacia branca, mas também para a masculina. Fazer florescer formas de igualdade substantiva no desértico contexto do estranhamento radical de uma sociedade escravocrata era uma afronta e um risco significativos à ordem estabelecida e ao sistema para o qual a subordinação era ontologicamente necessária: o capitalismo nascente.

Silvia Federici (2017) aponta para o vínculo genético e o câmbio constante entre formas de exploração escravistas e formas de exploração capitalistas. Parte significativa dos meios de vida necessários para a subsistência das trabalhadoras remuneradas das metrópoles era produzida pelo trabalho escravizado não remunerado nas colônias; enquanto, em contrapartida, os bens de consumo mais elaborados que passaram a compor a vida senhoril, comprados com o excedente produzido nas propriedades escravocratas, vinham das modernas indústrias do Norte do mundo. Havia também um intercâmbio ininterrupto das práticas de controle e disciplinamento das trabalhadoras e da organização do processo laboral entre essas duas esferas produtivas (Federici, 2017).

Esse vínculo genético entre as relações de exploração nas sociedades escravocratas e a acumulação (primitiva, mas não somente) de capital, bem como entre formas de trabalho não remuneradas e assalariadas - retomaremos esse vínculo com mais acuidade -, (co)formou e conformou (e assim segue) as distintas formas da feminilidade, em particular a feminilidade vivida pelas mulheres negras escravizadas.

Por ter sido o trabalho escravizado fundamental à acumulação (primitiva) de capital, fazia-se necessário uma retaliação à transgressão representada pelo apropriar-se ati- 
vo da igualdade negativa: lançar violentamente as mulheres escravizadas ao seu "lugar de fêmea". Consequentemente, a condição de mulher foi sempre mobilizada por senhores e capatazes - através dos constantes estupros e abusos sexuais aos quais eram submetidas - de modo a tanto discipliná-las quanto, em consequência, seus "irmãos" escravizados, na tentativa de reprimir as potencialidades emancipatórias que surgiam da igualdade substantiva experimentada na complementaridade com seus pares (Davis, 2016). Desse modo, apesar de as mulheres negras terem conseguido criar, no âmbito do trabalho doméstico, relações complementares, tendo experimentado, em alguma medida, formas de igualdade, sua condição de ser-mulheres foi amplamente mobilizada de modo a oprimi-las, bem como os seus companheiros.

A exploração do trabalho não pago e não remunerado pela ordem escravocrata instaurada nas colônias foi fundamental ao processo de acumulação do capital e, por sua vez, concomitantemente, o patriarcado foi instituição imprescindível ao funcionamento dessa ordem. Bell hooks compreende o patriarcado como geneticamente imbricado à escravidão:

\begin{abstract}
Sexismo institucionalizado - isto é, o patriarcado - formou a base da estrutura social americana estruturada juntamente com o imperialismo racial. O sexismo era uma parte integrante da ordem social e política que colonizadores brancos trouxeram com eles de suas terras europeias e teve um grave impacto sobre o destino das mulheres negras escravizadas (hooks, 2015: 30, tradução livre).
\end{abstract}

Nesse trecho, a autora oferece-nos outra importante pista: o arquétipo de exploração e opressão de mulheres foi trazido para as colônias pelo colonizador branco da Europa, não sendo resquício de relações "incivilizadas" a serem superadas, e independentemente do fato de o patriarcado ter sido adaptado aos diferentes contextos coloniais, com práticas distintas, de acordo com a multiplicidade das questões antropológicas e políticas postas por cada contexto regional, como as necessidades e os obstáculos locais, na extração de matérias-primas e produção colonial; a despeito das relações de gênero já consolidadas entre os povos colonizados e escravizados e das lutas de resistência que lhe opuseram².

Para o feminismo comunitário indígena, é preciso atentar-se às imbricações entre o patriarcado original e o patriarcado racista - capitalista, neoliberal. Ao levar em consideração as formas de opressão e exploração ancestrais da(s) mulher(es) indígena(s) que foi(ram) reconfigurada(s) no sistema patriarcal capitalista, Lorena Cabnal afirma:

A opressão manifestada contra as mulheres no interior de nossas culturas e cosmovisões é algo que há de se questionar de maneira
2. Para conferir materialidade ao processo de enraizamento do patriarcado nas colônias, respeitando suas singularidades, seria necessário uma análise detida das bibliografias que se debruçaram sobre as experiências coloniais locais - o que não se encontra no escopo deste artigo -, analisando, por exemplo, não só a diversidade das formas de escravidão negra e indígena, mas da servidão, como foram os casos da Índia, do Japão, da China e do Oriente Médio. Portanto, ao relacionar patriarcado e colonialismo, estou me pautando em uma reflexão dos aspectos mais gerais - embora analisando elementos da singularidade -, e que necessitam, posteriormente, ser expostos à confrontação com as experiências particulares para uma compreensão efetiva dessa articulação. 
frontal e nomeá-la tal como é: misoginia, expressada e manifestada nas atitudes e práticas cotidianas mais remotas e atuais contra nossos corpos, nossos pensamentos, decisões e ações (Cabnal, 2010: 18).

O feminismo comunitário compreende o corpo feminino e feminilizado como território fundamental da expropriação pelo patriarcado capitalista racista e, portanto, de resistência:

para nós, a recuperação do território corpo é uma recuperação histórica e não podemos adiá-la e não podemos dizer que a recuperação do território-terra é mais eminente [...] são realmente lutas simultâneas (Cabnal apud Bittencourt, 2015: 3).

Corpo que para cosmologia indígena não pode ser pensando desgarrado do território-terra. Cabnal propõe, portanto, compreender o território-corpo-terra como totalidade ontológica e epistêmica fundamental nas lutas diante do processo de expropriação crescente.

Refletir sobre as especificidades que o patriarcado, sob a égide da acumulação de capital, adquire ao se reestruturar, metamorfoseando-se, por meio das diversas formas que assume nas sociedades, às quais sua expropriação foi imposta, é fundamental para o desenvolvimento da categoria ser-outra proposta neste artigo, pois, embora eu esteja debruçando-me sobre sua construção no modo de produção capitalista, esse processo de "alterização" não pode prescindir da diversidade. Sua incorporação subalterna é a condição mesma de possibilidade da acumulação do capital.

Quanto ao patriarcado capitalista e racista, que parece alimentar-se de outros, há um processo histórico sob o qual, na Europa, se estruturou esse arquétipo - vou incorporá-lo a esse debate. Por ora, é importante frisar que sua exportação dada com a colonização funcionou como modo particular de controle da capacidade (pro) criativa das mulheres a serem expropriadas nas colônias e, de forma mais ampla, como instrumento para o enraizamento brutal do processo de colonização mesmo: "O objetivo político deste estupro categórico das mulheres negras por homens brancos era obter fidelidade absoluta e obediência à ordem imperialista branca" (hooks, 2015: 45, tradução livre).

As práticas sexistas foram amplamente mobilizadas para punir e controlar, não somente as mulheres escravizadas, mas também os seus parceiros (Davis, 2016), ao mesmo tempo que, ao incutir-se nos homens colonizados e escravizados, boicotou, 
constantemente, as formas de solidariedade comunais preexistentes e aquelas que estavam sendo gestadas como instrumentos de lutas anticoloniais.

Em sentido similar, Maria Mies (1998) analisa o aumento dos feminicídios e estupros na Índia pós-colonial. A autora se opõe ao argumento de que esse fenômeno estaria condicionado à permanência de estruturas estamentais pré-capitalistas, sendo expressão de resquícios de um patriarcado vernacular, e que, portanto, deveria ser enfrentado a partir da inserção dessas mulheres no mercado de trabalho. A socióloga e ativista alemã pauta-se na evidência de que o número de casos de violência contra as mulheres aumentou com a entrada da Índia no capitalismo competitivo, difundindo-se em todas as classes sociais do país, com significativa incidência entre os círculos mais modernos da sociedade indiana; concomitantemente, essa prática de violência cresce também no Ocidente. Concebe-se mesmo explicações psicologizantes, baseadas na psicanálise freudiana, que percebem o estupro como expressão patológica de uma pulsão inerente à masculinidade baseada na disputa e conquista de mulheres (Mies, 1998).

Isso porque o estupro e o assédio nas sociedades capitalistas fundam-se sobre o caráter denegado e não remunerado, todavia indispensável, do trabalho de pro(criação) e do cuidado de pessoas, em particular das crianças, sem jamais ter, de fato, dispensado de modo significativo o trabalho "produtivo" das mulheres ${ }^{3}$. A autora compreende como raiz dessa violência a separação fundamental entre trabalho não remunerado - tido como não produtivo - e trabalho remunerado "produtivo" (Mies, 1998).

Uma vez que a remuneração não é utilizada para o incentivo e o disciplinamento da força de trabalho, já que ela não é assalariada, fez-se necessário criar outros mecanismos para o controle desse contingente de trabalhadoras: o estupro, forma institucionalizada de coação e coerção, fulcral à escravidão e ao patriarcado, pilares por excelência da produção e acumulação de capital (primitiva e contemporânea). Vejamos outro trecho de hooks:

O tratamento brutal de mulheres negras escravizadas por homens brancos expôs as profundezas do ódio masculino à mulher e ao corpo da mulher. Esse tratamento foi uma consequência direta de atitudes misóginas em relação às mulheres que prevaleciam na sociedade da América colonial. No ensino fundamentalista cristão, a mulher era retratada como uma sedutora sexual maligna, que traz o pecado ao mundo. A luxúria sexual se originou com ela, e os homens eram apenas as vítimas de seu poder arbitrário. A socialização dos homens brancos, que levou a considerar as mulheres como sua queda moral, contribuiu para o desenvolvimento do sentimento antimulher (hooks, 2015: 48-49, tradução livre).
3. Para tanto, Mies analisa as trocas baseadas em doteesposa e aquelas baseadas preçoesposa. Na primeira, o casamento é mediado por uma quantia oferecida pela família da noiva, enquanto no segundo caso, é mediada por um valor oferecido pela família do noivo. Além de se opor ao sentido circular de ganhos monetários desses sistemas, atestando que essas trocas reafirmam a superioridade das famílias dos esposos sobre as famílias das esposas, Mies também ressalta que o dote-esposa torna ainda mais denegado o caráter produtivo do trabalho feminino. Isso em razão de ser concebido como taxa pelo consumo improdutivo das mulheres na estrutura familiar (Mies, 1998). 
4. Pierre Bourdieu oferece pistas interessantes para pensar processos de feminização das classes, raças e etnias, ou de racialização e etnicização dos gêneros e classes. Vale observar o seguinte trecho: "Através de cada um dos fatores exerce-se a eficácia de todos os outros, de modo que a multiplicidade das determinações conduz não à indeterminação, mas à sobredeterminação [...]" (Bourdieu, 2006: 101).
Outro importante elemento é um modo de sentir partilhado entre os homens, reproduzido nas práticas cotidianas, nos ensinamentos religiosos, e que pôde ser posto como tal na brutal violência infligida às mulheres negras escravizadas: a misoginia. O ódio às mulheres, ao corpo feminino, bem como àqueles elementos que passam a compreender uma certa feminilidade, é amplamente disseminado na construção da masculinidade inerente ao sistema capitalista e à estrutura, não se atendo apenas às relações entre homens e mulheres, como ainda entre as raças, as classes, as etnias ${ }^{4}$.

A subalternidade da ser-outra, em suas múltiplas condições e posições, passa a ser, em grande medida, simbolicamente conectada à feminilidade. Esta articula tanto a passividade, o horizonte do opressor, quanto o seu oposto necessário: o caráter corruptor, maléfico e destruidor das mulheres; sendo as mulheres, portanto, indignas de confiança, alvo de toda forma de desdém, assim como de vigilância e controle constantes. Sob o risco de subverter a ordem, as mulheres devem ser mantidas sob domínio.

Bell hooks cita o caso da perseguição e condenação de centenas de mulheres, que terminou com o enforcamento de pelo menos 20 delas, na cidade de Salem, entre os anos de 1692 e 1693, acusadas de bruxaria; episódio emblemático da misoginia inerente ao colonizador branco.

Silva Federici (2004) dedica-se em Calibã e a bruxa: mulheres, corpo e acumulação primitiva a analisar a acumulação primitiva partindo de uma perspectiva feminista. A autora mostra como o capitalismo surge e se efetiva pela imbricação entre cercamentos, escravidão, colonização e caça às bruxas, que foram reveses articulados contra as revoltas camponesas e urbanas, nas quais as mulheres foram importantes protagonistas, tanto da violência como da resistência diante da expropriação (Federici, 2017: 330).

A criminalização das práticas técnico-rituais que envolviam o controle da capacidade de pro(criação) das mulheres - seja da concepção, seja da contracepção - foi, por sua vez, responsável por destroçar brutalmente a unidade basilar que existia entre trabalho "reprodutivo" e trabalho "produtivo". Nesse caso, as mulheres enquanto produtoras de seres-humanas são expropriadas de seus meios de produção, isto é, de sua capacidade de pro(criação).

Houve a criminalização do aborto e do infanticídio (Federici, 2017). Todavia, para as mulheres negras escravizadas, a contracepção em suas várias técnicas, antes 
empregada no controle ativo de sua capacidade pro(criativa) - como o foi pelas mulheres nas mais diversas culturas - passa a integrar uma forma de resistência compulsória frente às condições perversas impostas pela escravidão (Davis, 2016) ${ }^{5}$.

E não apenas aquele conhecimento relacionado à concepção e à contracepção foi perseguido: toda forma de saber que envolvia o corpo feminino se tornou perigoso, um possível indício de bruxaria. Os ciclos menstruais tornaram-se momentos propícios à feitiçaria, ao contato entre as mulheres e o demônio - esse, tal como o sujeito homem branco e o deus-criador, tornou-se uma entidade poderosíssima como em nenhum momento da Idade Média, que escravizava as mulheres, submetendo-as aos seus caprichos sexuais. Arquirrival do deus-criador e do sujeito homem. Para os três competidores, as mulheres foram reduzidas a objetos - bem que com poderes mágicos a serem ora manipulados, ora temidos -, sendo possuídas e esposadas. 0 sangue menstrual tornou-se portador de capacidades mágicas e obscuras.

Marcel Mauss aponta que há uma linha muito tênue entre a arte (técnica) e a magia (ritual). Nas sociedades pré-capitalistas, o trânsito contínuo entre essas duas formas de modificação da matéria é explícito, pois a unidade social ainda não foi cindida; a magia tem, tal qual a arte, o poder de modificar formas e conteúdo. O autor dá o exemplo da medicina. Nas sociedades modernas esse trânsito, bem que explicitamente interditado, não seria jamais fechado, argumenta (Mauss, 2003).

A interdição explícita, no entanto, foi mobilizada como argumento para a expulsão das mulheres do espaço de cuidado das gestantes e do acompanhamento de partos, logo, com sua inclusão subordinada. As atividades e os conhecimentos que, até então, eram domínio feminino, passaram ao controle exclusivo dos homens: os obstetras passam a monopolizar a atividade, antes das parteiras, com o pretexto de expulsar toda a magia, ora considerada poderosa e nefasta, ora superstição ineficaz, todavia igualmente perigosa por não se embasar no conhecimento científico.

Ao mesmo tempo, essa interdição destituiu as mulheres do conhecimento global que tinham de seus corpos. O corpo feminino é percebido em cada canto como potencialmente mágico, compulsoriamente vigiado pela coletividade; às mulheres coube somente - garantindo, assim, sua sobrevivência - esquecer-se dele e, quando a força teimosa de sua concretude Ihes impunha sua existência, repudiá-lo.

As mulheres tiveram seus corpos aprisionados pelos opostos complementares desgraça/graça. Se as bruxas surgem encarnando toda a desgraça que esse corpo porta, Maria, mãe de Jesus, é a personificação da possibilidade de redimi-lo pela maternidade.
5. Em Amada, Toni Morrison (2007) conta a história da menina de dois anos que foi assassinada pela mãe, Margaret Garner, evitando que a criança fosse levada de volta à fazenda e submetida à escravidão.

O infanticídio e os abortos na história, longe de configurarem uma exceção, eram regra: "'Vou te contar, Sethe [é a mãe], menininha", e contou. Contou a Sethe que sua mãe e Nan tinham vindo juntas pelo mar. Ambas foram usadas muitas vezes pela tripulação. "Ela jogou todos fora, menos você. O da tripulação ela jogou fora na ilha. Os outros de outros brancos, ela também jogou fora. Sem nomes, ela jogou eles. Você ela chamou com o nome do negro. Ele ela abraçou. Os outros ela não abraçou. Nunca. Nunca. Estou te dizendo. Estou te contando, Sethe, menininha" (Morisson, 2011: 100-101). 
No sexto mês, o anjo Gabriel foi enviado por Deus a uma cidade da Galileia chamada Nazaré. Foi a uma virgem, prometida em casamento a um homem chamado José, que era descendente de Davi. O nome da virgem era Maria. O anjo entrou onde ela estava, e disse: "Alegre-se, cheia de graça! O senhor está com você!" Ouvindo isso Maria ficou preocupada, e pergunta a si mesmo o que a saudação queria dizer. O anjo disse: "Não tenha medo, Maria, porque você encontrou graça diante de Deus. Eis que você vai ficar grávida, terá um filho e dará a ele o nome de Jesus" (Lucas, 1, 26-31).

É importante ressaltar que essa contradição se abre como abismo para todas as muIheres, notadamente para as colonizadas, que, por suas condições objetivas - materiais e simbólicas (exemplo: a escravidão e a profissão de credo não cristão) -, não se enquadravam nessa dualidade. Para elas, graça/desgraça foi importante condição de desumanização, nem sequer eram enquadradas na definição perversa de muIheridade, importante mecanismo de expropriação de seus corpos.

Em um momento de queda populacional na Europa, provocada pelas guerras, pela fome e pelas pestes, estabilidade no processo de colonização da Ásia e África (que teve seu desenvolvimento a partir das Cruzadas) e início da colonização das Américas, expropriar e acumular necessitava de amplo contingente humano. Para manter a capacidade de pro(criação) das mulheres em correspondência com essa necessidade de crescimento vegetativo em uma sociedade em que a taxa de natalidade era baixa e os casamentos realizados tardiamente (Federici, 2017), a ascensão de um símbolo de pro(criação) não sexualizada, evidenciado na maternidade de uma virgem que resgatasse coercitivamente uma identidade feminina positiva, que havia sido destroçada pela Inquisição, foi fundamental.

Com a Virgem Maria, ascende o símbolo de uma mulher que, pela experiência de uma maternidade ancorada na renúncia sexual, mais ainda, na inexistência mesmo do ato sexual, e na aceitação das dores da obrigação de entregar o seu filho aos desígnios de um pai ausente, tem a desgraça do pecado original de Eva, transmutada em graça pela ação do deus-criador - que, no entanto, nunca lhe responde e opera através de um mensageiro, o anjo-homem Gabriel.

Ao mesmo tempo, era necessário punir aquelas mulheres (e homens) - a homossexualidade que, durante a Alta e Média Idade Média coexistiu, segundo Federici, com certa harmonia com a heterossexualidade normativa, passa a ser amplamente perseguida - que não exerciam uma atividade sexual pro(criativa). No caso específico das mulher(es), as viúvas idosas e aquelas que trabalhavam com a prostituição. Cabe ressaltar que a prostituição, na média Idade Média, havia sido, na França por 
exemplo, uma prática institucionalizada, na qual mulheres que a praticavam, bem que sem deixar de ocupar uma posição marginal, contavam com a valoração econômica e social. Na transição, as mulheres suspeitas de prostituição passam a ser socialmente perseguidas sem, no entanto, que esse serviço deixe de ser amplamente mobilizado por homens de todas as classes sociais ${ }^{6}$.

A velha e a prostituta, ao lado das mulheres colonizadas, serão símbolos da desgraça, da corrupção sexual, que torna a vida infértil. No caso das viúvas idosas, vale ressaltar que, além de não pro(criarem), com os cercamentos das terras comuns, passaram a ser consideradas um peso econômico improdutivo e potenciais agitadoras, já que eram presença constantes nos levantes (Federici, 2017).

Porém, a perseguição de formas não produtivas da sexualidade tinha como objetivo tanto perseguir e controlar a(s) mulher(es) como extirpar o prazer de toda e qualquer atividade sexual feminina, mesmo daquelas "produtivas". Sendo assim, não é de se estranhar que, ao final do processo de transição, com a ascensão hegemônica do capitalismo no século XVIII, o clitóris, enquanto órgão sexual feminino, tenha desaparecido. Segundo Margareth Rago (2002: 186), "[...] o orgasmo feminino é apagado, enquanto o clitóris é silenciado física e discursivamente."

É assim que a caça às bruxas, em um ataque amplo às mulheres e a qualquer forma de conhecimento e autonomia sobre seus corpos, ao mesmo tempo que criou as condições objetivas fundamentais para o desenvolvimento do capitalismo, retirando seu controle sobre sua capacidade pro(criativa) - podendo, desse modo, expropriá-la -, estabeleceu contra elas um estado permanente de terror e vigilância, desarticulando a participação que tinham nas lutas antifeudais e nas resistências frente ao modelo de produção em germe que se lhes opunha, sem ter de fato extinguido tal participação.

O novo patriarcado 7 que se ergue, com essa forma - primitiva - de expropriação e acumulação, nasce e se desenvolve articulando essas duas dimensões, e necessita tanto controlar a capacidade pro(criativa) das mulheres, transformando seu útero em "máquina de produção da força de trabalho", quanto desestabilizar a potencialidade feminina de resistência e luta (Federici, 2017). E essas duas dimensões conectam a exploração e opressão das mulheres em suas distintas condições e posições de ser-outra nas metrópoles e nas colônias.

Ao fundar-se sobre o controle da atividade pro(criativa), o patriarcado, no modo de produção capitalista, não se reduz, portanto, às mulheres que podem ou querem -
6. George Simmel escreve, em 1892, um pequeno ensaio sobre a prostituição na sociedade moderna-Algumas reflexões sobre a prostituição no presente e no futuro-, no qual nos oferece duas pistas bastante interessantes. De um lado, ele conecta o rebaixamento da prostituição enquanto atividade laboral à universalização do dinheiro como

"medida de todas as outras coisas": "Onde o dinheiro ainda não constitui a medida de quase todos os valores da existência na mesma medida que nós, portanto quando ainda é algo mais raro e menos usado, a cessão do bem pessoal em troca dele não é tão degradante". (Simmel, 1993: 5). De outro lado, ele expõe a hipocrisia moral do horror que a "boa" sociedade sente pela degradação causada por essa equivalência, enquanto naturaliza outra "Acaso ela não delega, sem outra formalidade, milhares de trabalhadores às minas destinando-os a uma existência que mal vê o sol e que dia após dia, ano após ano, é sacrificada em relação à sociedade [...]?" (Simmel, 1993: 8).

7. Novo patriarcado é uma das definições 
utilizadas por Silvia Federici (2017) em Calibã e a bruxa para nomear a estrutura patriarcal que ascende com o capitalismo. Segundo a autora, embora o patriarcado tenha existido em outras formas societais, incluindo a da Idade Média, é no modo de produção capitalista que ele se torna uma instituição de expropriação global dos corpos feminilizados. Assim, compreendo que mesmo quando se aproprie de estruturas patriarcais existentes nas sociedades não capitalistas sobre as quais avança, há uma metamorfose dessas, criando uma estrutura de opressão e exploração particular baseada no controle desses corpos para a produção da força de trabalho, ao mesmo tempo que retira o caráter ativo dessa atividade e a enclausura na esfera da reprodução biológica.

8. Disponível em: <https://www. jornaldocomercio. com/conteudo/ cultura/2019/ 02/668366-trio-asbahias-e-a-cozinhamineira-lanca-singlee-promete-novodisco-e-shows.html> Acesso em: 23 Mar. 2020.

9. Embora não haja dados precisos sobre a situação da(s) mulher(es) trans e travesti(s) no Brasil, sendo esse mais como questiona Judith Butler - ser utilizadas como produtoras do contingente de força de trabalho, mas explora e oprime todas a(s) mulher(es) - mesmo se com formas e intensidades distintas -, perseguindo, desde a gênese, as formas de vivência da sexualidade que não podem ser mobilizadas de modo produtivo: não por acaso, a violência contra mulheres trans, lésbicas e queers, assim como contra homens homossexuais, é estrutural e permanente no capitalismo. Portanto, enquanto o patriarcado for uma forma totalizante de exploração e opressão, as mulheres, em suas distintas posições e condições, permanecem sendo sujeito da luta feminista e anticapitalista.

Bruxas da contemporaneidade, a(s) mulher(es) transexual(is) e travesti(s) parece $(\mathrm{m})$ em muito transubstancializar a condição daquelas que foram perseguidas durante o processo de acumulação primitiva do capital, tornando nus alguns dos mecanismos da opressão e exploração patriarcal, muito vivos e estruturais que geralmente deveriam permanecer ocultos. Raquel Virgínia, cantora e compositora da banda As Bahias e a cozinha mineira, ressalta em uma entrevista ao Jornal do Comércio de Porto Alegre: "O nosso prazer, o gozo, a diversão está num limiar com a morte"

Perseguidas, assassinadas e enclausuradas na prostituição, quase como possibilidade exclusiva laboral e afetiva9 ${ }^{9}$, as mulheres trans e travestis no Brasil vivem, em média, 35 anos - menos da metade da expectativa de vida da população brasileira. Contra elas parece haver um verdadeiro estado de guerra.

Assim, a experiência sexual não "reprodutiva" surge como potência antipatriarcal e anticapitalista, desmitificando o caráter natural e imutável que tem vinculado ser-mulheres tanto à pro(criação) como à determinação biológica de seu sexo. A sexualidade feminina é, na experiência trans e travesti, imbuída de autonomia e autodeterminação inconciliáveis com as necessidades da acumulação de capital. Não me parece, portanto, mero acaso que o exercício da sexualidade das mulheres trans e travestis - sobreviventes ao genocídio cotidiano - precise tão logo ser realocado em uma atividade produtiva: a prostituição. Esta é, ademais, uma atividade laboral remunerada marginal e imprescindível, que concentra muitas das contradições que perpassam o capitalismo patriarcal racista.

Sobre elementos inerentes às relações patriarcais que a prostituição descortina, Patrícia Mattos (2018) afirma:

Aos olhos da "boa sociedade", a prostituta é repulsiva por ela intermediar o campo dos afetos explicitamente através da relação monetária, do dinheiro, ainda que implicitamente esse seja um elemento também presente em qualquer relação afetiva, embora nunca admitido (Mattos, 2018: 192). 
Em outras palavras, o ser-mulheres, como forma de alteridade absoluta produzida pelo patriarcado, fundamenta-se no controle da capacidade pro(criativa), estruturando a exploração e a opressão e nivelando todo o contingente de trabalhadoras. Isso ocorre tanto na esfera considerada "re(produtiva)" como naquela "produtiva". Ora, forçando-as a produzirem força de trabalho, negando-lhes o acesso livre e gratuito ao controle da "reprodução", ora impedindo-as de gestar, parir e criar suas crianças ou condenando-as à morte precoce, ao encarceramento, à miséria. Como Ressalta Talíria Petrone:

Porque, ainda hoje, mães são separadas de seus filhos - pelo injusto sistema carcerário, pelos assassinatos promovidos pelo Estado, pela desnutrição, pela extrema pobreza ou pelo desemprego. E porque também hoje, como aquelas mulheres, há milhões que estão à frente de lutas por justiça social, pela vida de seus filhos, pelo direito de existir com dignidade e alegria (Petrone, 2020).

E mais: a perseguir as formas de sexualidade e performances de gênero que não podem estar sob o comando de suas necessidades de demanda.

O patriarcado, em sua forma contemporânea, nasce simultaneamente à acumulação de capitais, estruturando-a ao mesmo tempo que é estruturado por suas necessidades, isso porque sem trabalhadoras e trabalhadores detentores da força de trabalho, seja ela remunerada ou forçada, não há produção de mercadorias e "serviços", a despeito do amplo processo de mecanização do trabalho.

O patriarcado mantém o trabalho realizado na esfera doméstica - pro(criação), cuidados e todas as atividades laborais que mantêm esse espaço funcionando - subalterno às determinações do trabalho realizado fora do espaço doméstico. Não por acaso, a igualdade substantiva experimentada, em alguma medida, pelas mulheres negras estadunidenses em relação aos seus pares nessa esfera, durante a escravidão, foi bastante frágil, sendo corrompida sistematicamente pela supremacia branca, mas também pela adesão dos homens negros às práticas e visão de mundo sexistas.

A ênfase no sexismo intrínseco às práticas dos homens negros, mesmo antes do final escravidão, é um elemento que distingue substancialmente as argumentações de Angela Davis e bell hooks. Enquanto Davis confere centralidade à solidariedade entre mulheres e homens negros, concentrando o protagonismo da exploração e da opressão dessas mulheres nos homens brancos e proprietários e conferindo

um obstáculos para a construção de políticas públicas que as incorpore, estimase que cerca de 90 a 95\% das mesmas estejam trabalhando como profissionais do sexo (Almeida \& Vasconcellos, 2018). 
lugar de destaque à igualdade conquistada na esfera doméstica, hooks discorda dessa concepção:

Embora mulheres e homens negros tivessem lutado igualmente pela libertação durante a escravidão e em grande parte da era da Reconstrução, líderes políticos negros do sexo masculino sustentavam valores patriarcais (hooks, 2015: 17, tradução livre).

Hooks denuncia o fato de que, se as mulheres negras foram forçadas a exercer as atividades consideradas como prática masculina nas plantações, todavia não era solicitado aos homens negros escravizados que exercessem atividades domésticas, consideradas femininas, de cuidadores das casas e das crianças dos senhores (hooks, 2015: 122).

Se nem sempre as diferenças socialmente constituídas entre homens e mulheres configuraram-se em privilégios aos homens negros escravizados, elas, contudo, representaram sempre uma hierarquia.

Bell hooks se opõe radicalmente à romantização das relações entre mulheres e homens negros, que ela denuncia como um tanto funcional, seja ao feminismo branco das classes médias e altas, seja aos líderes negros:

\footnotetext{
Feministas brancas estavam tão focadas na disparidade entre macho branco/fêmea branca como uma indicação do impacto negativo do sexismo em seu status econômico que não chamavam atenção para o fato de que homens pobres e de classe baixa são tão capazes de oprimir e brutalizar as mulheres como qualquer outro grupo de homens na sociedade americana. [...] A rotulagem do patriarca masculino branco como "porco chauvinista" forneceu um bode expiatório conveniente para os negros machistas sexistas. Eles poderiam se juntar com mulheres brancas e negras para protestar contra a opressão masculina branca e desviar a atenção para longe de seu sexismo, seu apoio ao patriarcado e sua exploração sexista das mulheres (hooks, 2015: 121, tradução livre).
}

No primeiro caso, a ignorância diante das relações sexistas que pautavam as relações das classes pobres, bem como sofrida pelas mulheres negras e ainda pelas imigrantes, permitiu que o feminismo branco das classes média e alta, em outras palavras, o feminismo liberal, focasse suas pautas na igualdade econômica entre homens e mulheres. Ao mesmo tempo, manteve os privilégios da exploração e da opressão da força de trabalho proletária, negra e imigrante, configurada, justamente, por essas relações. No mesmo sentido, apontam Cinzia Arruza, Tithi Bhattacharya e Nancy Fraser: 
Completamente compativel com a crescente desigualdade, o feminismo liberal terceiriza a opressão. Permite que mulheres em postos profissionais-gerenciais façam acontecer precisamente por possibilitar que elas se apoiem sobre mulheres imigrantes mal remuneradas a quem subcontratam para realizar o papel de cuidadoras e o trabalho doméstico (Arruza, Bhattacharya \& Fraser, 2018: 38).

No segundo caso, os líderes negros, em particular a partir dos anos 1960, não somente se silenciavam diante do sexismo, como o reproduziam nas práticas cotidianas com suas parceiras afetivas e de luta e, sobretudo, em seus discursos sobre a autodeterminação do povo negro. Bell hooks afirma que muitos dos militantes do movimento Black Power - dentre alguns, ela trata dos escritos e discursos do poeta Amiri Baraka -, na luta genuína pela emancipação do racismo, não percebiam que, embora propusessem a construção de uma forma distinta de sociedade que rompesse radicalmente com a supremacia branca, ao não se questionarem e, em alguns casos, reproduzirem deliberadamente as estruturas sexistas e heteronormativas que a sustentavam, não somente contribuíam à emergência de um patriarcado negro que explora e oprime as mulheres negras (hooks, 2015: 134) como, apesar de terem conquistado alguns importantes avanços nas condições de vida e sobrevivência do povo negro, mantiveram-no a serviço da ordem cuja pretensão era destruir.

Se Angela Davis e bell hooks não compartilham posição no que tange à solidariedade ou à exploração/opressão entre homens e mulheres negras, ambas concordam que as mulheres negras enfrentaram tanto o racismo quanto, em radicalidade, a condição de ser-mulheres. Analisar em que medida há concordância com a tese de uma ou de outra é um trabalho que ultrapassa o objetivo que me coloco neste artigo. No entanto, devido à seriedade dos trabalhos de ambas, arrisco conjecturar que, em grande medida, é possível estar de acordo com as duas: a história dos oprimidos, em sua pluralidade, tem sido perpassada ora por momentos de solidariedade e complementaridade, ora por disputas e hierarquizações e exploração e opressão. Opto, portanto, por apreender as diferenças, com essas ênfases distintas, que me permitem captar o movimento dialético dessa relação entre solidariedade e rupturas que transpassa a forma ser-outra.

Por exemplo, a luta das mulheres americanas negras e brancas foi gestada e parida no interior do movimento abolicionista. Um dos momentos importantes, segundo Davis, foi o levantar das mulheres brancas de classe média em apoio à luta antiescravagista. Esse levante teve um papel imprescindível nas conquistas empreendidas: elas financiaram congressos abolicionistas, promoveram literatura antiescravista, mobilizaram-se pelo acesso de meninas (e meninos) e mulheres (e homens) 
negras(os) à educação formal, acolheram mulheres e homens escravizadas(os), ajudando-as(os) em rotas de fuga. Ao mesmo tempo, a militância ativa, entusiasmada e comprometida dessas mulheres, trouxe-Ihes condições e aptidões para questionarem a condição de exploração e opressão à qual estavam submetidas (Davis, 2016).

Davis, em sua análise, traz um processo histórico no qual as lutas emancipatórias ora confluem, e há experimentações potencialmente revolucionárias da unidade das diferentes formas de exploração e opressão; ora têm diferenças concebidas enquanto rivalidades, móveis de disputas, sendo percebidas como obstáculos intransponíveis.

10. Em Amada, a personagem Baby Suggs traz, de modo visceral, não somente o drama da maternidade negada mas a brutalidade da desumanização, da alteridade absoluta conferida ao outro, tratado como peça, e a contradição da humanidade que se mantém teimosa, resistente, experimentada pelo choque: "Então, os oito filhos de Baby Suggs eram de seis pais. O que ela chamava de maldade da vida era o choque que ela recebia ao saber que ninguém parava de jogar as peças só porque entre as peças estavam seus filhos. Halle foi o que ela conseguiu conservar mais tempo. Vinte anos. Uma vida inteira. Coisa que the foi dada sem dúvida, como compensação ao ficar sabendo que suas duas filhas, nenhuma das quais tinha ainda dentes permanentes,

haviam sido vendidas e mandadas embora e que ela não pudera nem acenar adeus" (Morisson, 2011: 47).
As mulheres brancas, ao se levantarem por sua emancipação, encontraram grande resistência dentro do movimento abolicionista, em especial dos homens brancos, cujos questionamentos e ridicularização passavam pela defesa da supremacia masculina frente à ideologia da feminilidade frágil física e intelectualmente, do confinamento dessas mulheres à esfera doméstica e, portanto, de sua incapacidade natural e intransponível para o exercício das atividades públicas, desde permanecerem e discursarem no salão principal das assembleias até o acesso ao sufrágio.

Encontraram, no entanto, em alguns importantes líderes negros abolicionistas, parceiros de luta: Frederick Douglass, considerado o pai do movimento pelos direitos civis nos Estados Unidos foi, provavelmente, um dos mais leais e empenhados (Davis, 2016). E assim nasce o movimento de mulheres norte-americano: irmão de sangue do movimento antiescravista.

\section{Considerações finais: \\ o patriarcado racista e a acumulação de capitais}

A exploração e a opressão intrínsecas à condição de ser-mulher foram, como frisado antes, uma dimensão reconhecida pelas mulheres negras que lutaram contra a escravidão no século XIX, sendo expressa de modo literal no questionamento central do discurso de Sojourner Truth - "Não sou eu uma mulher?" -, cuja condição de ser mulher, bem que repleta da singularidade de uma mulher negra fazendo-se na e contra a escravidão - no trabalho forçado, arando e colhendo, com castigos físicos -, sem qualquer regalo pela pretensa fragilidade feminina, remete, sobretudo, à exploração e à opressão sexual, pelos estupros e abusos institucionalizados, mas também à exploração pro(criativa). Sojourner, assim como as mulheres europeias de diferentes classes, foi submetida há um número exorbitante de gestações e partos (13), mas não pôde, de fato, viver a maternidade, tendo suas filhas e filhos arrancadas de seu convívio, vendidas enquanto mercadorias ${ }^{10}$. 
Das mulheres negras escravizadas, a quem, com a proibição do tráfico de mulheres e homens negras, se impõe o trabalho pro(criativo), foi, no mais das vezes, retirada a possibilidade de cuidado de suas filhas e filhos - cuidado esse que constitui a estrutura do mito da maternidade ${ }^{11}$ (Davis, 2016). No entanto, ao mesmo tempo, foram forçadas a cuidarem das crianças dos senhores e, por meio cuidado, fundou-se a imagem da mulher negra enquanto símbolo da doçura maternal: a ama de leite, a "mãe preta", a "bá". Segundo Lélia Gonzalez (1984):

Ela, simplesmente, é a mãe. É isso mesmo, é a mãe. Porque a branca, na verdade, é a outra. Se assim não é, a gente pergunta: quem é que amamenta, que dá banho, que limpa cocô, que põe prá dormir, que acorda de noite prá cuidar, que ensina a falar, que conta história e por aí afora? É a mãe, não é? Pois então. Ela é a mãe nesse barato doido da cultura brasileira. Enquanto mucama, é a mulher; então "bá", é a mãe. A branca, a chamada legítima esposa, é justamente a outra que, por impossível que pareça, só serve prá parir os filhos do senhor. Não exerce a função materna. Esta é efetuada pela negra. Por isso a "mãe preta" é a mãe (Gonzalez, 1984: 235).

A voracidade da expropriação experimentada pelas mulheres escravizadas não apenas torna nu o que o mito da maternidade branca e ocidental oculta, mas, antes, foi protoforma para o desenvolvimento de uma dimensão fundamental da forma ser-mulheres: os corpos feminilizados foram transformados em máquinas de produção (gestar, parir e cuidar) da mercadoria essencial à produção capitalista: a força de trabalho. As mulheres escravizadas gestavam e pariam as crianças que seriam comercializadas e colocadas, tão logo fosse possível, a produzir valor, ao mesmo tempo que foram imprescindíveis ao cuidado, formando as crianças dos senhores.

No que diz respeito às mulheres indígenas, em particular na América Latina, a combinação perversa entre a institucionalização do estupro de mulheres e meninas indígenas com a etnocida política estatal de retirada legal das crianças de suas famílias e tribos ${ }^{12}$ tem sido eficaz para o processo que as feministas indígenas chamam de penetração patriarcal capitalista (Cabnal, 2010). Nesse processo, se estabelece o controle violento dos corpos feminilizados e racializados, ao mesmo tempo que se apropria das crianças - futura força de trabalho. Ao arrancar as crianças indígenas daqueles vínculos que as conectam aos territórios que a acumulação capitalista ainda não expropriou totalmente, abre-se caminho à expropriação territorial.

Silvia Federice (2017), como vimos, demonstrou a articulação fundamental entre cercamentos e expropriação dos corpos feminilizados; as feministas comunitárias
11. Há uma separação velada entre o gestar e parir e o cuidar representada pela imagem do "embalar": dos primeiros, todo caráter ativo e autodeterminado são retirados; quanto ao segundo, o caráter de abnegação transforma-o em uma atividade humana subalterna, mas, mágica, no sentido de Mauss, trabalhado anteriormente.

E é sobre os cuidados que se sustenta o mito da maternidade.

12. De acordo com dados do Conselho Indigenista Missionário (Cimi), de 2018,60\% das crianças que estavam em instituições de acolhimento à criança e ao adolescente em Dourados (MT) eram de alguma etnia indígena. Disponível em: < https://cimi. org.br/2018/03/ racismo-institucionaljustificando-pobrezaestado-retiracriancas-de-suasfamilias-guarani-ekaiowa/>. Acesso em 07 Abr. 2021. 
têm demonstrado a articulação entre penetração patriarcal capitalista e expropriação violenta do território-corpo e do território-terra (Cabnal, 2010; 2015).

O que a condição e posição das mulheres negras e indígenas nos revelam?

Controlar o trabalho de maternagem, seja impondo-o compulsoriamente, seja impedindo-o, é fundamental para a acumulação capitalista. Para tanto, separar os trabalhos de gestar/parir e de cuidar é fundamental.

Ao impor a maternidade compulsória por meios violentos, como a institucionalização do estupro, forma-se, por meio da penetração patriarcal capitalista, uma classe de mulheres proletarizadas - negras, indígenas, imigrantes - capaz, como venho frisando, de fornecer a força de trabalho; isto é, gerar a mercadoria primordial para o processo de produção do capital, isso porque "o trabalho vivo tem que se apoderar dessas coisas e despertá-las dos mortos" (Marx, 2013: 260).

Paralelamente, impedir o exercício da maternação dessas mulheres, ou condicioná-lo à precariedade, cria as condições de possibilidade para lhes transferir parte significativa da produção da força de trabalho qualificada e da gestão do capital: mercadoria bastante cara, da qual o capital não pode prescindir, que possibilita não apenas a sua gerência - nas instituições públicas e privadas -, mas a criação direta de valor, através da produção de tecnologias das mais diversas a serem agregadas às mercadorias em sua multiplicidade.

Destarte, a separação entre o processo de trabalho fundamentalmente imbricado à capacidade pro(criativa) - gestar e parir - daquele direcionado aos cuidados torna a improdutividade que pretensamente pauta o trabalho reprodutivo, legitimando a condição de ser-outra - em potência - duplamente imprescindível e, de fato, produtiva ao capital: ao produzir a força de trabalho stricto sensu (a classe trabalhadora) e ao participar ativamente da produção das classes dirigentes.

Ressalto, todavia, seguindo as pistas de Maria Mies, que a noção de tempo de trabalho socialmente necessário, basilar à teoria do valor, funda-se sobre uma epistemologia masculina e branca. O trabalho, enquanto categoria, é determinado por esse situar-se particular. Segundo Maria Mies, o capitalismo não pressupõe, na verdade exclui de forma estrutural o trabalho feminino (seja ele remunerado ou não) enquanto equivalente possível nas relações de troca; por isso ele surge enquanto improdutivo, lançado ao âmbito da reprodução social e não da produção social. As teorias sobre o capitalismo tenderam a tomar esse fator fundamental à acumulação como dado, sem questioná-lo. Em suas palavras: 
Este conceito [capitalismo] exclui por definição as tarefas domésticas e gravidez e cuidado das crianças da categoria de "trabalho produtivo" e, assim, reduz as mulheres a uma unidade de consumo (Mies, 1998: 159, tradução livre, grifos meus).

É por não compreender o caráter denegado do trabalho feminino no processo de produção capitalista que Marx, ao desenvolver a noção de valor, não leva em consideração o caráter particular que envolve a definição de tempo de trabalho socialmente necessário ${ }^{13}$ à produção da força de trabalho enquanto mercadoria equivalente a todas as demais. Embora o tempo de trabalho socialmente necessário empreendido na pro(criação) e cuidados seja de difícil cálculo, é, sem grandes constrangimentos, de fácil expropriação.

Mies propõe uma definição de trabalho que seja feminina. Um dos pilares da definição proposta é repensar a separação entre tempo de trabalho e tempo de lazer. Como pensar o tempo de trabalho socialmente necessário para os trabalhos de pro(criação) e cuidados, nos quais o tempo de trabalho coloniza, em grande medida, o tempo lazer?

A gestação, com a exaustão e o desgaste físico e emocional, tampouco se encerra nos períodos de sono: o trabalho de gestar a força de trabalho é ininterrupto porquanto dure a gravidez. No tempo em que os cuidados exigidos na formação da ser-humana, em particular no primeiro setênio, atravessam madrugadas, desconhecem pausas para descanso e alimentação ${ }^{14}$. Em outras palavras, é preciso pensar tempo de trabalho socialmente necessário levando em consideração jornadas de trabalho ininterruptas ou com breves pausas.

Mas há outro elemento que particulariza uma medição do trabalho despendido pelas mulheres na pro(criação) e nos cuidados: a intensidade. Se a dimensão do gozo, como também aponta Mies, é presença determinante nesse processo de trabalho, a intensidade também o é, ao mesmo tempo que é de difícil cálculo. É preciso um estudo detido para compreender a especificidade da intensidade do processo de trabalho inerente ao gestar e parir e cuidar. Por exemplo, a mulher gestante produz cerca de $50 \%$ a mais do volume sanguíneo habitual. O cuidado envolve uma modificação psíquica na atenção, que é também química, assim, até mesmo em períodos de sono, o corpo mantém determinadas funções em alerta. Se somarmos essa intensidade às ausências de sono e à alimentação adequada, bem como aos múltiplos trabalhos domésticos cuja realização as mulheres ainda concentram e, para a grande maioria, o exercício de uma atividade remunerada, a intensidade do trabalho das mulheres parece-me imensurável pelas medições oficiais.
13. O tempo de trabalho socialmente necessário é o tempo médio de trabalho humano despendido para a produção de mercadorias. Vejamos como Marx define dispêndio de trabalho humano:

"Ele é dispêndio da força de trabalho simples que, em média, toda pessoa comum, sem qualquer desenvolvimento especial, possui em seu organismo corpóreo. Embora seu caráter varie em diferentes países e épocas culturais, o trabalho simples médio está dado em toda e qualquer sociedade existente. O trabalho mais complexo vale apenas como trabalho simples potencializado ou, antes, multiplicado, de modo que uma quantidade menor de trabalho complexo é igual a uma quantidade maior de trabalho simples. Que essa redução ocorra constantemente é algo mostrado pela experiência. Mesmo que uma mercadoria seja o produto do trabalho mais complexo, seu valor a equipara ao produto do trabalho mais simples e, desse modo, representa ele próprio uma quantidade determinada de trabalho simples (Marx, 2017: 122).

14. Para se pensar no tempo de trabalho socialmente 
necessário em trabalhos de pro(criação) e cuidados, uma pista interessante é acompanhar grupos de mães nas redes sociais, tais como Instagram, Facebook e WhatsApp. A quantidade de postagens e conversas realizadas na madrugada é bastante indicativa de jornadas de trabalho ininterruptas. O conteúdo dessas postagens e conversas se divide em duas frentes: denúncia, na qual a falta de redes de apoio societais (públicas e comunitárias) se evidencia; troca de informações baseadas em evidências científicas
Portanto, ao falar da produção de seres-humanas, é necessário questionar a categoria tempo de trabalho socialmente necessário, seja em sua extensão - jornada de trabalho - seja em sua intensidade. Essa é uma questão que não pretendo resolver, mas apenas apontar para algumas contradições a partir da bibliografia aqui trabalhada.

E, a despeito de ser opaca, essa sua peculiaridade é estrutural à acumulação, pois, por meio dela, o capitalismo pôde, ao mesmo tempo, não remunerar o tempo de trabalho socialmente necessário à pro(criação) e aos cuidados, rebaixar o valor do trabalho exercido pelas mulheres na esfera "produtiva" e sub-remunerá-las naqueles trabalhos tratados com improdutivos, pois não geram diretamente mais-valor.

Coube e cabe, majoritariamente, às mulheres o triplo trabalho de gestar, parir e cuidar da formação de sua classe, bem como da formação das classes médias e burguesas por meio dos cuidados (Guimarães, Hirata \& Sugita, 2011). Em outras palavras, cabe às mulheres, de modo insuperável e exclusivo - por serem detentoras exclusivas da capacidade de pro(criação) -, uma parte significativa do fazer-se de sua classe, ao mesmo tempo que a divisão do trabalho, que é também sexual e racial, as lança ao fazer-se das classes dirigentes e proprietárias do capital. Sem que com isso deixem de exercer, em larga escala, as atividades que têm o monopólio conceitual da "produção".

O mito da maternidade tem permitido que, além de gerada, a força de trabalho possa ser formada quase exclusivamente pelas mulheres, com baixíssimos custos ao capital - seja trabalhando na formação de suas crianças ou na das demais classes. 0 custo da "reprodução" das/os futuras/os trabalhadoras/es realizada pelas mulheres, é, apenas parcialmente, incluída nos salários, e rebaixa ainda mais o preço da força de trabalho, aumentando, portanto, a extração de trabalho não pago (Saffioti, 2013).

Diante do fato de as mulheres produzirem a mercadoria imprescindível à produção de valor - a força de trabalho -, esse trabalho é pago apenas parcialmente, seja através dos salários das mães - atualmente, no Brasil, apenas 7\% das mulheres declaram exercerem exclusivamente o trabalho doméstico (Folha de S. Paulo, 2019) -, dos pais, ou, ainda, das aposentadorias de avós e avôs. Dessa forma, com o rebaixamento do custo da força de trabalho, não me parece possível seguir afirmando que o trabalho pro(criativo) e de cuidados, sejam eles realizados para a própria família, sejam realizados para outrem (remunerado ou não), não participe diretamente da produção de mais-valor, sendo, portanto, trabalhos produtivos ao capital. Não se pretende, todavia, no escopo deste artigo, avançar nessa questão, mas apontá-la, pois, é a partir dela que as relações entre atividade e passividade, produção e reprodução, que são inerentes à constituição da ser-outra se desenvolvem. 
A despeito das distinções, parece haver um arquétipo de patriarcado, desenvolvido na Europa, que o colonizador trouxe consigo para as colônias - sob o qual as formas de exploração colonial ganharam corpo e sangue. Em resumo: o patriarcado, enquanto forma intrínseca e basilar à acumulação capitalista, é forma total e totalizante de exploração e opressão das mulheres. Ao mesmo tempo, é uma categoria política construída, apropriada e enfrentada pelos diversos feminismos, estando, portanto, ativamente presente no fazer-se da ser-outra.

Portanto, levando em conta os argumentos desenvolvidos neste artigo, podemos dizer que o patriarcado racista, tal como se desenvolve no capitalismo, singulariza-se pela necessidade insuperável de controle da pro(criação) humana, por conseguinte, das mulheres, lançando-as à condição de ser-outras.

\section{Referências}

A BÍBLIA. São Paulo: Paulus, 1990.

ADICHIE, Chimamanda Ngozi. O perigo de uma história única. São Paulo: Companhia das Letras, 2009.

ALMEIDA, Cecília Barreto de; VASCONCELLOS, Victor Augusto. Transexuais: transpondo barreiras no mercado de trabalho em São Paulo? Rev. Direito GV, v. 14, n. 2, São Paulo, Maio-Ago. 2018.

ARRUZA, Cinzia; BHATTACHARYA, Tithi; FRASER, Nancy. Feminismo para os 99\%: um Manifesto. São Paulo: Boitempo, 2018.

BEAUVOIR, Simone. O segundo sexo. Rio de Janeiro: Nova Fronteira, 2016 [1949].

BOURDIEU, Pierre. A distinção: crítica social do julgamento. São Paulo; Porto Alegre: Editora USP; Zouk, 2006 [1979].

CABNAL, Lorena. Acercamiento a la construcción del pensamiento epistémico de las mujeres indígenas feministas comunitarias de Abya Yala. In: . Feminismos diversos: el feminismo comunitario, p. 11-25. Huntington Park, CA: Las Segovias Acsur, 2010.

A recuperação do corpo como território defesa. Entrevista a Juliana Bittencourt. Revista Geni, 2015. Disponível em: <http://revistageni.org>. Acesso em: 20 Jan. 2020. 
CARBY, Hazel. White woman listen! Black feminism and the boundaries of sisterhood. Black British Cultural Studies. Chicago, 1996.

COLLINS, Patricia Hill. Pensamento feminista negro. São Paulo: Boitempo, 2019.

CONDÉ, Maryse. Eu, Tituba. Bruxa negra de Salem. Rio de Janeiro: Rosa dos tempos, 2019.

DAVIS, Angela. Mulheres, raça, classe. São Paulo: Boitempo, 2016 [1981].

FEDERICl, Silvia. Calibã e a Bruxa: mulheres, corpo e acumulação primitiva. São Paulo: Elefante, 2017 [2004].

FOLHA DE S. PAULO. Parcela da população que se declara dona de casa cai para $7 \%$ em 26 anos. Folha de São Paulo, 6 Ago. 2019. Disponível em: https://www1.folha. uol.com.br/mercado/2019/08/parcela-da-populacao-que-se-declara-dona-de-casa-cai-para-7-em-26-anos.shtml >. Acesso em : 07 Ago. 2019.

GONZALEZ, Lélia. Racismo e sexismo na cultura brasileira. Revista Ciências Sociais Hoje, Anpocs, p. 223-244, 1984.

GUIMARÃES, Nadya Araujo; HIRATA, Helena; SUGITA, Sumiko Kurumi. Cuidado e cuidadoras: o trabalho de care no Brasil, França e Japão. Revista Sociologia \& Antropologia v. 1, n. 1, p. 151-180, 2011.

HOOKS, bell. Da margem ao centro. São Paulo: Perspectiva, 2019 [1984].

Ain't i a woman: black women and feminism. New York; London: Routledge, 2015 [1981].

MARX. Karl. O capital: crítica da economia política. Livro I. São Paulo: Boitempo, 2013 [1867].

MAUSS, Marcel. Sociologia e antropologia. São Paulo: Cosac Naify, 2003.

MATTOS, Patrícia. A dor e o estigma da puta pobre apud SOUZA, Jessé. A ralé brasileira: quem é como vive. São Paulo: Contratempos, 2018 [2009].

MBEMBE, Achille. A crítica da razão negra. São Paulo: N-1 Edições, 2018 [2013].

MIES, Maria. Patriarchy \& accumulation on a word scale: women in the International division of labor. New York: Zed Book, 1998 [1986].

MORISSON, Toni. Amada. São Paulo: Companhia das Letras, 2007 [1987]. 
PETRONE, Talíria. (Re)nascer em tempos de pandemia. Pandemia capital. São Paulo: Boitempo, 2020.

RAGO, Margareth. Os mistérios do corpo feminino ou as muitas descobertas do "amor venéris". Proj. História, n. 25, São Paulo, Dez. 2002.

RANIERE, Jesus. A câmara escura: alienação e estranhamento em Marx. São Paulo: Boitempo, 2001.

RIBEIRO, Djamila. O que é lugar de fala? São Paulo: Pólen Livros, 2019.

SAFFIOT, Heleieth. A mulher na sociedade de classes: mito e realidade. São Paulo: Expressão Popular, 2013 [1969].

SIMMEL, George. A filosofia do amor. São Paulo: Martins Fontes, 1993.

VERGÈS, Françoise. Um feminismo decolonial. São Paulo: Ubu, 2020. 